\title{
Experiencing Innovation Practice Applied to Computer Science Courses via Innovation Framework
}

\author{
Diones Hohemberger, Andréia dos Santos Sachete, Fábio Diniz Rossi \\ IFFar, Brazil
}

\begin{abstract}
Technology transitions are speedy, and universities often hope to associate with industry requirements. Based on the advent of Industry 4.0, curriculum changes must be continuous. Contemporary scholars must be professionals who can discover new answers, make decisions based on data, and interact with different fields. Incorporating entrepreneurial practice into innovations in computer courses can academically promote scholars' viewpoints that are vital to the world today, such as collaboration, problem-solving, holistic views, networks, protagonists, and creativity. This work recommends the use of an innovation framework to improve this capability. Steinbeis-SIBE University introduces a new approach, and the framework increases the stages of design thinking in more meaningful quantities to guide clearly defined actions. The result of the approach point is that most of the work that has been developed can become an innovation that supports local and regional development.
\end{abstract}

\section{Introduction}

The way we construct knowledge defines us. In other words, if knowledge is provided in the academy based on a fragmented path -- if the curriculum components are not integrated and do not follow the learning plan for the overall development of the student -- it is unlikely to develop into a complete and indivisible Citizen. The fragmentation of the scientific knowledge to be taught is exposed in the disciplinary separation of the college and is harmful to education. However, in the context of a given topic, knowledge is allocated to some relatively impeccable content, which is provided in a separate and unplugged manner. The fragmentation of teaching is a lack of meaning, which is manifested in scholars as a rejection of specific disciplines, indicating that students cannot understand the relationship and correlation between different fields of knowledge.

Just as important as the human concepts that people hope to teach is understanding relational knowledge. The field of expertise-and its content, arrangement, and worldview-can be observed through excellent integration. In the field of education, interdisciplinary [1], multidisciplinary [2] and interdisciplinary [3] methods have been researched to overcome the fragmentation of the curriculum [4] through the creation of very technical and scientific disciplines, and eventually generate college dynamics, in which students are responsible A bridge between knowledge, not a curriculum. Although, the biggest challenge is how to integrate the curriculum without giving up the many knowledge production designs carried by the domain? How to make learning more meaningful by interacting knowledge with daily life?

For curricular integration to suit the important world within the academy, the Political Pedagogical Project (PPP) must state new methods of handling administration and collaborative effort among lecturers [5]. An approach to realizing this is often to determine practices common to all areas concerning effective teaching and learning methodologies (cooperative learning, project learning, or research and problem-solving), including formative and procedural assessment procedures [6].

Fieldwork, projects, complex problem-solving, and end-of-course work are samples of integration activities that aim to learn, relate them, and involve students and lecturers in projects that end in essential knowledge of fundamental skills that fill the whole curriculum. Group work is additionally an excellent challenge for all at any age. In today's society, it's an important ability, which aims to market collaboration and foster learning within the coordination of various roles, self-control, articulation, and management of tasks, research, planning, and construction.

This work introduces an innovation framework to assist curricular integration. It contributes to the vocational affirmation of the scholar within the chosen area of action, although providing the event of applications that will reinforce local and regional rise.

This paper is organized as follows: In section 2, we present a discussion about the difficulties of integrating the curriculum and a few literature proposals that attempt to address such difficulties; In Section 3, we present Steinbeis-SIBE innovation framework and its applicability as a viable solution to such limitations; In section 4 we present a proper practice combining several disciplines towards innovation projects; In section 5 we present and discuss the products resulting from such practice; In 
section 6 we end with our conclusions and future work.

\section{Related Work}

Now, there's no more place for solely technical education, which only prevailed for the event of specialties - supported the scientific development of data. This path crystallized the academy history marked by the disciplinary fragmentation [7] [8], during a departmental arrangement that crosses the constitutive cycles of the course. Though, this paradigm shift is required but challenging to accomplish in practice.

Interdisciplinarity rose from the demand to beat the fragmentation caused by a positivist epistemology at the top of the last century. The sciences were divided into several disciplines, and interdisciplinarity renewed a minimum of dialogue among them. Considered by the science of education as an organic relation of the topic discipline and applied domain, interdisciplinarity has become an admitted term within the academy because it's seen as how of thinking.

In this way, interdisciplinarity would be how to obtain transdisciplinarity, a stage that might not be within the interaction and interchange between the sciences but would reach a stage where there would be no more barriers among the disciplines. Currently, interdisciplinarity has been welcomed by most educators since such an edge globally ensures the development of data, breaking with the boundaries of disciplines because only the mixing of content would not be enough.

The logic behind is simple: if reality may be a complex and broad one, fragmented education doesn't consider for understanding it in its entirety, making it as required because it is essential to exchange and dialogue among disciplines during the method of the meaningfulness of both content of the planet during which we live. Additionally, interdisciplinarity reveals special skills in scholars, like curiosity, interest in learning, and therefore the ability to figure in groups. At an equivalent time, it leads to significant leads to scholars' performance and their development as social beings.

Faced with the progressive globalization of the economy [9], the conditions for forming a replacement professional are emphasized, with flexibility stressed at the expense of specialization. From this, and for safeguarding the pliability of curricular organization, interdisciplinarity takes strength given the delineation of a replacement formative pathway. Consistent with this new methodology, several proposals attempt to address the restrictions imposed by the non-integration of the disciplines.

Perhaps the most popular among all proposals for integration between disciplines is within the sort of project development [10]. In such a model, several fields run during the academy year specializing in a process or product that ought to be ready at the top of the term. Each subject contributes to some skills necessary for the processes or products, which the students may develop individually or uniquely throughout the category.

However, this sort of integration isn't something officially regulated unless it's curricular. Integration of curricular disciplines [11] doesn't offer the chance of not occurring combination through projects or the other chosen methodology. This model has given rise to higher technology courses that provide only one formation but also a more general primary formation. The scholar can choose the formative path to follow from a particular point, thus selecting a more specific area.

Teaching alongside research is an option that has always worked well in stricto sensu programs and has also been utilized in secondary and better education courses [12]. This model lets the scholar be updated and in line with a selected study object and enhance their knowledge by taking advantage of the supervision of a specialist lecturer within the chosen area.

A proposal that, additionally to being interdisciplinary -- the transdisciplinary -- consists of projects integrated by teams of students from different areas and courses [13] [14]. This model expands the chances of projects with new ideas because researchers within the area alone cannot solve many problems of a selected area. Generally, computation has done well in this role, supporting the resolution or speed up in solving physics, biology, and chemistry problems, among others.

From the mixing of tangible sciences emerges STEM, a movement of integration between Science, Technology, Engineering, and arithmetic. STEM proposals range from projects applied in infancy education [15] to education [16]. The approach involves scholars in hands-on activities that combine different knowledge and cause creative learning.

\section{Framework}

We are faced with the challenges of a company world, marked by technology and competitiveness, the event of software products and services needed to stay the pace. To the present end, so-called agile methods have emerged. Agile Software Development involves a group of methodologies that accelerate the pace of software development processes [17].

Since its origin dates back to the mid-1990s, the Agile concept was soon spread among the experts, leading to different models that support project management. The agile methods suggest addressing traditional development models, which are slow and bureaucratic, to scale back the event cycle in weeks 
or months - in conservative models, and this cycle can last for years. Therefore, assuming that the projects have an outlined beginning and end which they're planned and developed piecemeal, a number of the most characteristics - besides agility - of the agile methods are incremental process (almost an antithesis of the standard cascade model), customer collaboration, adaptability (each project is subject to various modifications), simplicity, constant feedback, small teams (but with a high technical level).

Several frameworks that support the agile methodology are created, and that we can mention the most methods: Feature Driven Development (FDD) [18], Extreme Programming (XP) [19], Microsoft Solutions Framework (MSF) [20], Dynamic System Development Model (DSDM) [21], and Scrum [22].

FDD's [18] basic premise is that it specializes in functionality, allowing the project team to perform incremental planning. This sort of action helps offer agility to the event of solutions in environments of utmost uncertainty, where changes are inevitable. FDD programming starts with the business overview since this method considers the sum of everything more significant than each of the parts separately. We then proceed to the detailing of the merchandise with the subdivision by areas to be modeled, culminating within the description of every function.

XP [19] is an agile method focused on software development supported by three pillars: agility within the answer, resource-saving, and quality of the ultimate product. To realize excellence within the services provided, and XP team must be valuesbased, a contract of attitudes and behaviors that cause success. These behaviors and attitudes guide the actions of the XP team in each activity to be performed, ensuring the mixing and synergy necessary for permanent performance. Additionally, to the values, the agile XP method also considers better working practices, aiming to provide the effectiveness of the XP team's work and customer satisfaction throughout the event process.

MSF [20] is one of the agile methods most used for technological solutions by small teams, specializing in reducing risks to the business and increasing the standard of the ultimate product. The aim is to spot the main common flaws in technology projects, mitigating them and improving the success rates of every initiative.

DSDM [21] is one of the oldest agile methods used in project development and technology. A touch different from the opposite agile methods, it's aimed toward the event of projects with a tight and fast budget and short deadlines, considering that the client has no way of knowing what proportion the ultimate solution will cost. Among its best practices are incremental and iterative development, a collaboration between client and team, and functionalities integration, which we also see in other agile methods. It's worth noting that DSDM differs from other agile methods in its structure, which consists of interconnected processes of modeling, design, construction, implementation, and time management, which isn't flexible until the functionalities change. Still, since then, the deadlines for implementation remain equivalent.

Scrum [22] is the most generally used agile method today, especially since it is often easily integrated with other agile methods, applying not only to software development but also to any work environment. With attention to project management, Scrum is predicated on iterative and incremental planning, which occurs, as explained, by the meetings referred to as Sprints - this point, we'll approach the concept intimately. From the start of the project, it reiterates the list of functionalities to be developed - practice also called, during this case, product backlog. Within the process progress, each feature becomes a Sprint, whose details to be created and developed go from the merchandise backlog to the sprint backlog. From the sprint backlog, the activities are distributed among the members of the Scrum Team, who must develop them within a deadline that sometimes takes no quite four weeks. At the top of every sprint, the sprint review meeting, an alignment meeting on what was delivered, is held. From there, you start to plan subsequent sprints. These steps happen in succession until the ultimate product is prepared for delivery.

Additionally, to those already established methodologies, an approach has been happening. Design Thinking [23] may be a way of the approach taken from the design sector and tailored to companies and corporations. Design Thinking is seen as a group of practices and processes that proposes a replacement approach to problems. This is often associated with obtaining information, its analysis, and the resulting solutions offered from the generated knowledge. The main target becomes the buyer's experience or the audience, looking for answers to the issues found through Design Thinking as a methodological approach. The many difference of this method is that it starts from the solution, from the project, and not necessarily from all the parameters of the matter, as is common within the methodology. The steps assigned to style thinking are immersion, ideation, prototyping, and development. The method, from immersion to development, seek innovation during a non-linear way, the attribution and discovery of latest values and meanings for projects, services, and products, also because the constitution of integrative thinking as a tool to succeed in solutions, not strictly definitive, but holistic and supported the experience of the buyer.

The framework proposed by the Steinbeis School of International Business and Entrepreneurship 
(SIBE - https://sibe-edu.com) consists of joining the most straightforward practices of most frameworks supported by agile methods. Figure 1 shows the life cycle of such a framework.

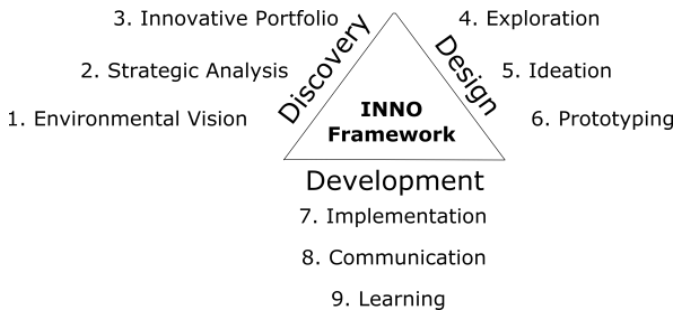

Figure 1. Steinbeis-SIBE Innovation Framework

It consists of an expansion of design thinking to define the main target of the products to be developed and define all phases of the project. Also, it uses Scrum sprints for every new step, active collaboration between client and development team like DSDM, performs risk analysis like MSF and performs small deliveries like PDD and XP. This framework is split into three dimensions: discovery, design, and development. The invention dimension includes the phases of environmental vision, strategic analysis, and innovation portfolio. The planning dimension consists of the exploration, ideation, and prototyping phases. And therefore, the development dimension consists of implementation, communication, and learning phases. For every step, a selected tool was used.

\section{Teaching Practice}

The Integrated Professional Practice (IPP) consists of a teaching methodology that proposes to make sure space and time at the curriculum, allowing the connection between the knowledge inbuilt the various disciplines of the course and therefore the world. In this way, it's possible to customize the curriculum and expand the dialogue between different areas of activity.

Currently, it is a practice widely disseminated and implemented in vocational training institutions, being a crucial piece for the event of practical activities correlated to the course [24]. In one class of the computing area, the target of IPP is to look for theoretical and practical knowledge to base the selection of the discipline which will be developed and providing the students to mix the concepts studied daily with the practice, predicting their professional use. Therefore, it's evident that the IPP has as its focus the overcoming of curriculum fragmentation [25] and consequently the look for a curriculum that creates sense and aiming to the scholar. It's possible to spotlight during this practice the intention to operationalize the vertical combination of the curriculum, providing unity throughout the course, comprising a logical sequence and an increasing deepening of the knowledge in touch with the particular work practice, constituting as a permanent space of reflection-action involving the whole faculty of the course in its planning.

IPP is strongly influenced by STEM learning [26] [27], where the first idea is to unite knowledge of those four areas around the construction of something that solves the proposed challenge. STEM works within the sort of creative workshops so that scholars in groups can solve some challenges practically. The most thing is that it's a practical challenge that needs knowledge from different areas.

During this work, we present an IPP that considers a whole innovation framework to define the fields of action of future projects to be implemented. We believe that inventions that solve local problems have a more significant potential to become an innovation, allowing an improvement within the lifetime quality of such a community. The IPP was proposed through the mixing of three disciplines: (i) technological innovation, (ii) prototyping of hardware and software, and (iii) development of mobile applications.

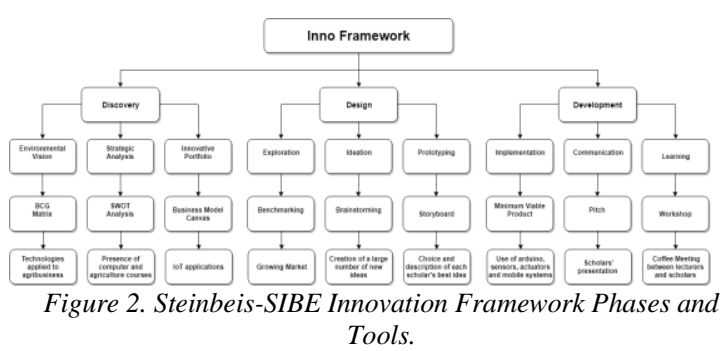

The discipline of technological innovation consists of working concepts and practices focused on innovation through technical products applied to local and regional development. Figure 2 presents all the size, their phases, tooling, and therefore the result. The framework is split into three dimensions. Each dimension is divided into three phases. Each phase presents main objectives and a few findings.

The results in Figure 2 demonstrated that our campus is found in a region that features a robust agricultural vocation. Our university offers courses and counts on specialists within the farming and computing areas. This set of things guided the work of IPP to the web of Things (IoT) applications [28] because it may be a paradigm that will compile all the areas addressed towards local and regional development.

The hardware and software prototyping discipline consist of developing hardware and software solutions that will be prototyped during a small electronics lab through inexpensive, easy-toimplement open-source platforms. Proposed projects 
used Arduino (or a number of its variants) [29], which consists of a board with a microcontroller and a few complementary components that aim to facilitate projects for reading electronic sensors and actuators expansion modules.

The discipline of development of mobile applications [30] consists of learning technical knowledge about the Android Software Development Kit (SDK) architecture, library features, besides good practices for mobile programming apps. The bulk of the lectures are focused on the practical aspect, developing and deploying smartphones applications. Also, we developed a final software package for Android mobile devices that communicate with the Arduino through digital communication modules (such as $\mathrm{WiFi}$ ) and permit the reading of values coming from the sensors and manipulation of the actuators. Internally, Arduino uses a variant of the $\mathrm{C}$ language, except for development on Android mobile devices, we used Java programing language. Therefore, the mixing among the three disciplines occurred as follows: within the innovation class, the students defined their potential in developing new products aligned with the requirements of the local productive arrangement (LPA). They participated during a creative process that resulted in one idea per scholar, which solves one among the restrictions investigated within the LPA. Each of the solutions was prototyped and implemented in conjunction with the 2 technical disciplines. The products generated were presented to an interdisciplinary committee and had their potential evaluated. It had been a flash of learning and socialization of data, ensuring an area destined for the main target of professional training, constituting a flash of reflection, which encouraged research and promoted interdisciplinarity.

\section{Results}

Agriculture, livestock, and aquaculture are a source of subsistence for a large part of the rural population who maintain small and medium-sized farms and produce agricultural products for their consumption and sale to the urban population. The outcomes of these segments consist of an essential source of income and employment for the field, usually performed by teams formed from a family unit. The data show that this economic activity is present in $85 \backslash \%$ of rural properties in Brazil, and $70 \backslash \%$ of the food consumed in the country is produced through this segment, the southern region of Brazil is the second largest producer (http://www.fao.org). This is the scenario that our research is established, and it was pointed out by the mechanisms of the innovation framework.

After defining each scholar's research theme, the prototypes to be developed were established, and are listed below:
- Automatic feeder for fish: the region is a major producer of fish in confined tanks. In most, the feeding is carried out manually. The proposal implemented an electro-mechanical device, which at predefined hours of the day, pour in the water of the tank an amount of fish feed.

- Automated greenhouse: several small producers keep greenhouses for the production of vegetables. Factors such as humidity and temperature should be controlled. The proposal implemented moisture and temperature sensors that drive greenhouse cooling devices when minimum and maximum limits are reached.

- A system of automation of irrigation of the soil: the region maintains a strong vocation concerning the production of grains. Grain crops, especially rice, need a layer of water to develop. The control of this layer of water is usually done manually. The proposal implemented through depth sensors dispersed in the plantation, a monitor in the opening of the siphons that allow managing the amount of water to be scattered in the plantation.

- System for detecting carbon monoxide and flammable gases: industries must control the amount of carbon monoxide in order to maintain the health of their employees. This proposal implemented through gas sensors, an alert for high levels of carbon monoxide.

- System for the control of entrance or exit of people: several institutions must control the presence of its employees. The proposal implemented radio frequency identification cards to manage entry and exit of employees on an electronic point card.

- Lighting control system for studios: home automation is an area that automates the management of electrical and mechanical devices in homes. The proposal implemented a centralized control of lights and appliances so that the owner of the residence can trigger any device through only one interface.

- Checking for spinal problems: Spinal problems such as lordosis, kyphosis, and scoliosis are quite common these days. The proposal implemented through a range of positioning sensors, a device that can generate a 3D image of a person's column and show the type of curvature of the column and its degree.

The driver devices were developed in the discipline of prototyping of hardware and software, and the user interface was developed in the discipline of development for mobile devices. Therefore, all prototypes can be controlled or display reports to users through mobile applications developed by scholars. It makes all proposed solutions more dynamic and up-to-date, and attractively presented to future investors. 
Such prototypes were presented to a group of researchers and evaluated regarding innovation potential. From now on, these jobs will pass through investor, and the chosen ones will become startups who can develop their products for the productive market. Therefore, what started as an IPP may have fostered the entrepreneurial spirit in scholars, to the point that when they graduate in the graduation course, they already have their companies selling their products.

\section{Conclusion}

A few years ago, the organization of scholarly knowledge by disciplines had been the purpose of criticism starting from the argument that disciplines represent more of an outcome to education than social, cultural, and political issues underpinning the tutorial policies that guide the organization of academy curricula. However, the most critical of the curricular disciplinary approach is that the fragmentation of data. Among the choice proposals to the organization of academy knowledge by disciplines, those specializing in interdisciplinarity, and curricular integration stand out.

This traditionally fragmented model doesn't cause an increase in innovation. An environment conducive to innovation is one during which there's a clash of ideas. People of varied experiences and specialties must be present within the creation process, and these moments of creation must be structured to supply results. Another point of stimulus to diversity is the possibility that exchanges occur in any direction, be it between peers and other people from very different areas. An innovative environment was proposed and supported by IPP.

Interdisciplinarity via IPP can materialize in teaching methodologies, curriculum, and teaching practice. From the historical perspective that reveals that data fragmentation is accentuated with labor fragmentation, one must remember that sorts of work organizations, which don't specialize in completeness, can emphasize the fragmentation of faculty knowledge.

IPP allowed several issues to be addressed. They were approaching the campus with LPA, one among the missions of upper education institutions, which consists of developing the region during which the campus is found. Scholars experienced a real-world innovation environment, from a vision of open development opportunities to design prototyping solutions. Also, they need to experience the principal current development methodologies, like design thinking, agile methods, and project management. Finally, each scholar features a finished product with potential patent registration and, therefore, the possibility of opening a startup aimed toward marketing such a product. Besides, IPP understands different situations of experience, learning, and work, guided by research as a pedagogical principle, whose purpose is to articulate knowledge through the mixing of the disciplines within the course and to bring the training of students closer to the planet of labor.

As future work, the products will be presented in rounds of investors to capture resources and boost the creation of startups. Regarding teaching, the practice of IPP will be adopted as a complementary activity to the scholar's education, continuously and absorbed by the current curriculum of the technology courses.

\section{References}

[1] Martin, T., E. Coupey, L. McNair, E. Dorsa, J. Forsyth, S. Kim, and R. Kemnitzer. 2012. "An Interdisciplinary Design Course for Pervasive Computing." IEEE Pervasive Computing 11 (1): 80-83.

[2] Newman, K. E., I. R. Jones, C. L. Reed, and C. McRae. 2007. "A multidisciplinary course to implement bioengineering design projects for persons with disabilities." In 2007 37th Annual Frontiers In Education Conference - Global Engineering: Knowledge Without Borders, Opportunities Without Passports, Oct, T2H-19T2H-20.

[3] Brookes, W. 2017. "Transdisciplinary learning in technology degrees." In 2017 16th International Conference on Information Technology Based Higher Education and Training (ITHET), July, 1-6.

[4] Machanick, Philip. 2003. "Principles versus artifacts in computer science curriculum design." Computers Education 41 (2): 191 - 201.http://www.sciencedirect.com/ science/article/pii/S0360131503000459.

[5] Nightingale, Karl P., Vikki Anderson, Susan Onens, Qulsom Fazil, and Helen Davies. 2019. "Developing the inclusive curriculum: Is supplementary lecture recording an effective approach in supporting students with Specific Learning Difficulties (SpLDs)?" Computers Education 130: 13 - 25.http://www.sciencedirect.com/science/article/ pii/S0360131518303038.

[6] M, V., M. S. Patil, A. S. Nayak, V. S. Handur, and G. S. Hanchinamani. 2018. "Enhancing Students Learning Skills Through Integrated Course Project Design Model (ICPDM)." In 2018 IEEE 18th International Conference on Advanced Learning Technologies (ICALT), July, 30-33.

[7] L. Greendorfer, Susan. 1987. "Specialization, Fragmentation, Integration, Discipline, Profession: What is the Real Issue?" Quest 39: 56-64.

[8] Balietti, Stefano, Michael Ms, and Dirk Helbing. 2015. "On Disciplinary Fragmentation and Scientific Progress." PLOS ONE 10: 1-26. https://doi.org/10.1371/journal.pone. 0118747.

[9] Miltenoff, Plamen, Jared Keengwe, and Gary Schnellert. 2011. "Technological Strategic Planning and Globalization in Higher Education." IJICTE 7 (3): 51-61. 
[10] Taajamaa, V., T. Westerlund, Xing Guo, M. Hupli, S. Salanter, and T. Salakoski. 2014. "Interdisciplinary engineering education - Practice based case." In Fourth Interdisciplinary Engineering Design Education Conference, March, 31-37.

[11] Goroshnikova, T. A., and E. S. Smakhtin. 2018. "Interdisciplinary Curriculum Approach as a University Component for Large-scale Education Projects." In 2018 Eleventh International Conference "Management of largescale system development" (MLSD, Oct, 1-4.

[12] Moh, M., R. Alvarez-Horine, S. S. Chandawale, and S. A. Mogarkar. 2013. "On interdisciplinary student background: A successful course integrating teaching and research." In 2013 3rd Interdisciplinary Engineering Design Education Conference, March, 56-62.

[13] Khoo, M. C. K. 2012. "Linking Engineering and Medicine: Fostering Collaboration Skills in Interdisciplinary Teams.” IEEE Pulse 3 (4): 27-29.

[14] Polutnik, J., M. Druzovec, and T. Welzer. 2013. "Interdisciplinary projects Cooperation of students of different study programs." In 2013 24th EAEEIE Annual Conference (EAEEIE 2013), May, 215-218.

[15] Zokowski, P., K. Geramita, J. Ashdown, B. Brooks, and A. Thompkins. 2016. "Connecting Kids to STEM through entrepreneurship and innovation." In 2016 IEEE Integrated STEM Education Conference (ISEC), March, 71-74.

[16] Nite, S. B., M. Margaret, R. M. Capraro, J. Morgan, and C. A. Peterson. 2014. "Science, technology, engineering and mathematics (STEM) education: A longitudinal examination of secondary school intervention." In 2014 IEEE Frontiers in Education Conference (FIE) Proceedings, Oct, 1-7.

[17] Gelperin, David. 2008. "Exploring Agile." In Proceedings of the 2008 International Workshop on Scrutinizing Agile Practices or Shoot-out at the Agile Corral, APOS '08, New York, NY, USA, 1-3. ACM.

[18] Ge, Xiaocheng, Richard F. Paige, Fiona A.C. Polack, Howard Chivers, and Phillip J. Brooke. 2006. "Agile Development of Secure Web Applications." In Proceedings of the 6th International Conference on Web Engineering, ICWE '06, New York, NY, USA, 305-312. ACM.

[19] Newkirk, James, and Robert C. Martin. 2000. "Extreme Programming in Practice." In Addendum to the 2000 Proceedings of the Conference on Object-oriented Programming, Systems, Languages, and Applications (Addendum), OOPSLA '00, New York, NY, USA, 25-26. ACM.

[20] Anderson, David J. 2005. "Stretching Agile to Fit CMMI Level 3 - the Story of Creating MSF for CMMI R Process Improvement at Microsoft Corporation." In Proceedings of the Agile Development Conference, ADC '05, Washington, DC, USA, 193-201. IEEE Computer Society.
[21] Sullivan, Kevin, and Jeff Magee. 2005. "Science of Design." In Proceedings of the 27th International Conference on Software Engineering, ICSE '05, New York, NY, USA, 46-46. ACM.

[22] Schwaber, Ken. 2004. Agile Project Management With Scrum. Redmond, WA, USA: Microsoft Press.

[23] Richards, L. G. 2017. "Special session: Learning design thinking using engineering case studies." In 2017 IEEE Frontiers in Education Conference (FIE), Oct, 1-3.

[24] Bashirova, Masuma, and Alymkan Sattarova. 2018. The Use of New Teaching and Learning Technologies for Professional Qualification Development in the System of the Initial and Secondary Vocational Education, 111-115. Cham: Springer International Publishing.

[25] Gilliland, Martha W., and Amelia A. Tynan. 2010. "Transforming Higher Education: Overcoming the Barriers to Better Schooling." The Solutions Journal 1 (6): 51-61. https://www.thesolutionsjournal.com/article/transforminghigher-educationovercoming-the-barriers-to-betterschooling/.

[26] Fowler, Allan. 2017. "Engaging Young Learners in Making Games: An Exploratory Study." In Proceedings of the 12th International Conference on the Foundations of Digital Games,FDG '17, New York, NY, USA, 65:1-65:5. ACM.

[27] Land, Michelle H. 2013. "Full STEAM Ahead: The Benefits of Integrating the Arts Into STEM.” In Complex Adaptive Systems.

[28] Miraz, Mahdi H., Maaruf Ali, Peter S. Excell, and Rich Picking. 2017. "A Review on Internet of Things (IoT), Internet of Everything (IoE) and Internet of Nano Things (IoNT)." CoRRabs/1709.10470.

[29] Margolis, Michael. 2012. Arduino Cookbook Recipes to Begin, Expand, and Enhance Your Projects: Covers Arduino 1.0 (2. ed.). O’Reilly.

[30] Karam, Orlando, and Richard Halstead-Nussloch. 2012. "Introducton to Android development." J. Comput. Sci. Coll. 28 (2): 224-224. 